\title{
Deciphering Possible Association of Risk Factors for Dental Caries in Pakistani Population
}

\author{
Shahida Maqsood, Hasan Baber (D, Zia Abbas, Javeria Ali Khan, and Muznah Khalid \\ Dow University of Health Sciences, Karachi, Pakistan \\ Correspondence should be addressed to Hasan Baber; relicpassion@yahoo.com
}

Received 25 July 2017; Accepted 3 January 2018; Published 28 February 2018

Academic Editor: Gilberto Sammartino

Copyright (c) 2018 Shahida Maqsood et al. This is an open access article distributed under the Creative Commons Attribution License, which permits unrestricted use, distribution, and reproduction in any medium, provided the original work is properly cited.

Obesity is a state of abnormal accumulation of fat in adipose tissues of the body to the level that one's health is adversely compromised. Tripathi et al. state (according to WHO) that obesity is now considered the fifth leading cause of mortality in the world. Caries is a multifactorial disease and one of the major oral health issues of the modern era affecting people around the globe. Rise in dental caries has been observed in developing countries as a result of factors including increased intake of carbohydrates. The present study aims for assessing the association of DMFT with BMI, age, and gender. This study was conducted in the dental OPD of the Dow University of Health Sciences, Karachi, from February 2016 till January 2017. A custom-made interview-based questionnaire was used to assess BMI, DMFT, and sociodemographics. The sample size was kept at 385. Age was reported as a strong predictor $\left(R^{2} 0.641\right)$ of DMFT followed by BMI and gender as the weakest predictors. Age and BMI had statistically significant association with DMFT scores, which shows that diet patterns may affect general health. High caloric intake over long periods affects BMI and also oral health.

\section{Introduction}

According to WHO, obesity is a state of abnormal accumulation of fat in adipose tissues of the body to the level that one's health is adversely compromised [1]. Alm et al. and Tripathi et al. state (according to WHO) that obesity is now considered the fifth leading cause of mortality in the world [2]. Reports suggest that the prevalence of obesity in the last two decades has doubled in developed and developing countries [3]. Association of obesity with certain systemic diseases such as type 2 diabetes, hypertension, and cerebrovascular diseases have been strongly reported in literature [3-7].

A comprehensive study of the National Health and Nutrition Examination Survey (NHANES) between 1999 and 2004 reported among individuals of 20-34 years had 85.58\% DMFT, 35-50 years had 94.30\% DMFT, and 50-64 years had $95.62 \%$ DMFT [8]. This suggests that DMFT score increases with age. In recent years, due to increase in refined, fat diet, and sedentary lifestyles, obesity has increased in South Asia. As highlighted by Amin et al., one major factor of obesity is change in regional diet and its quantity and quality [9]. Recent studies have demonstrated an increase in the consumption of animal and refined foods with reduction in the intake of vegetables [10].

Caries is the main cause of dental pain and loss of tooth [11]. It accounts for one of the major oral health-related diseases especially among younger individuals. Due to caries being so widespread globally, it is present among both genders, all age groups, and among all cultures and socioeconomic classes [12]. Dental caries not only results in financial burden but also has a major impact on the quality of life of an affected individual. Treatment of dental caries is also expensive. According to a WHO report, caries is the 2 nd most costly disease in Australia followed by cardiovascular diseases [13]. Progression in caries,prevention, and treatment regimens are achieved via scientific research. In the last ten years, a reduction in dental caries has been observed in developed nations $[14,15]$. Contrary to this, a rise in dental caries has been observed in developing countries as a result of factors including an increase in the intake of carbohydrates and high-sugar diet in the form of desserts, increase in 
people with low-socioeconomic status, lack of education, and basic health-care services [16]. A number of studies have been documented assessing the association of BMI and dental caries with conflicting results. The present study aims for assessing association of DMFT with BMI, age, and gender.

Our null hypothesis is that BMI, age, and gender are not associated with DMFT (caries), and BMI and age are weak predictors of DMFT.

Our alternate hypothesis is that BMI, age, and gender are associated with DMFT (caries), and BMI and age are strong predictors of DMFT.

\section{Methodology}

The study was conducted in the dental OPD of the Dow University of Health Sciences, Karachi, between February 2016 and January 2017. No issues were observed during routine patient care, as this study had no direct involvement regarding patient treatment or intervention. A custom-made questionnaire was used to assess BMI, DMFT, and sociodemographics of participants via an interview available here). Consent was obtained from all participants before the study. Keeping the confidence interval at $95 \%$ with standard error of mean at $0.5 \%$, the calculated sample size (considering annual patient flow in OPD) was 385. Participants within the age group of 14 to 65 years old were included. Edentulous patients were excluded. Patients having any communicable disease or any psychotic disorder or patients who have conditions restricting them to a very strict diet regimen, patients with radiation therapy, and pregnant women were also excluded.

BMI was categorized as underweight $(\mathrm{BMI}<18.5)$, normal (BMI 18.5-24.9), overweight (BMI 25-30), and obese (BMI $>30$ ). Participants were inquired regarding their eating habits, frequency of eating, consumption of refined sugars, snacks and fast foods, physical activity, and toothbrushing habits.

Caries prevalence was assessed via standard criteria set up by the WHO, the decayed, missing, and filled teeth (DMFT) index. The index determines the total number of dentition, surfaces of teeth having caries, and missing or had restorative procedures. Clinical dental examination was undertaken by house officers specially trained in dental OPD, with the use of natural sunlight or a source of illumination wherever needed. In accordance with infection control guidelines, new cap, mask, and gloves were used for each patient. Questions regarding lifestyle were assessed by the time spent on watching TV, use of computers, playing games on consoles or computers, and use of smart phones for the purpose of entertainment.

\section{Statistical Analysis}

Data were analyzed using the Statistical Package for Social Science software, version 20.0 (SPSS, Chicago, IL, USA). The chi-square test was used to study the relationship between variables and to compare means. $p$ value $<0.05$ was considered statistically significant. Linear logistic regression

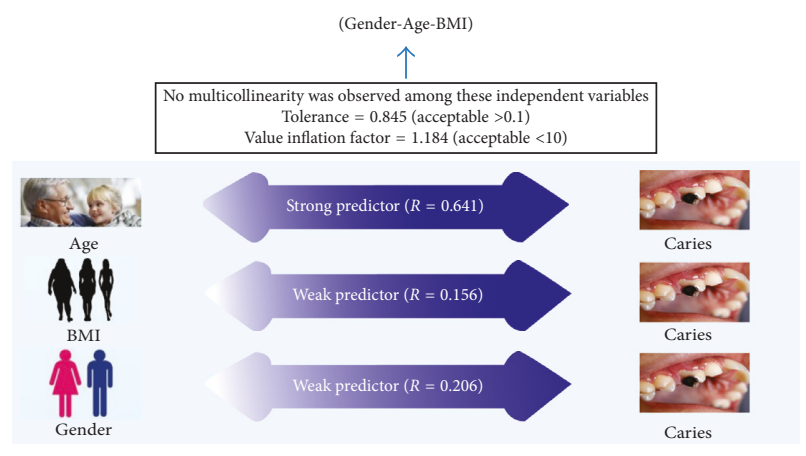

Figure 1

TABle 1

\begin{tabular}{lc}
\hline Age groups & $\begin{array}{c}p=0.001 \\
\text { DMFT }\end{array}$ \\
\hline Teenagers (14-19) & 28 \\
Young adults (20-40) & 19 \\
Adults (41-65) & 338 \\
\hline
\end{tabular}

analysis was used to determine the degree of association between obesity and dental caries and other variables.

\section{Results}

A total of 385 patients were enrolled in the study. The mean age was 24.60 years, and the mean DMFT was 3.01. Young females constitute the highest number of participants. Results are tabulated in Figure 1 and Tables 1-3.

With regard to possible associations between variables, age and BMI had demonstrated statistically significant association with DMFT scores. According to our results, $R^{2}$ of $64.1 \%$ variance in age can be a strong predictor of DMFT score, while BMI (15.6\%) and gender (20.6\%) variance is not good enough in predicting DMFT scores of an individual.

\section{Discussion}

Both dental caries and BMI are related to diet-related health outcomes, and the association between the two is not surprising. Previously, past studies have also reported the association between these two variables [17]. Since the mid1990s, there have been drastic changes in lifestyle and diet, probably due to the increased usage of food having rich calories and intake of carbohydrate drinks and foods. This can be one of the etiological factors of rise in obesity and dental caries [17-19]. Obesity has seen a rise in the US and Europe [20]. According to Eurostat's statistics, a report published in 2014 states that European Union states as of 2014 had staggering $51.4 \%$ of population above 18 years. A similar report of NHANES (National Health and Nutrition Survey) in a 2012 survey states that US individuals above 20 years having BMI of 30 plus [21]. The present study had less overweight individuals than those with normal BMI; thus, the majority of high DMFT score was among normal weight individuals; probably here factors determining caries are 
TABLE 2

\begin{tabular}{lc}
\hline Gender & $p=0.301$ \\
Male & DMFT \\
Female & 92 \\
\hline
\end{tabular}

TABle 3

\begin{tabular}{lc}
\hline BMI & $\begin{array}{c}p=0.003 \\
\text { DMFT }\end{array}$ \\
\hline Underweight & 42 \\
Normal & 298 \\
Overweight & 45 \\
Obese & 27 \\
\hline
\end{tabular}

others such as poor oral hygiene, lack of education, and so on. The result was as expected as according to Wan Siang et al. Asian countries have some of the lowest prevalences of overweight and obesity worldwide, with Vietnam and India having the lowest with $1.7 \%$ and $1.9 \%$, respectively [22].

Older adults demonstrated highest number of DMFT scores. A survey by the National Institute of Dental and Craniofacial Research between 1999 and 2004 reported the age group of 20-34 years constituting the highest number of decayed untreated teeth, but with lowest DMFT score. The current study also demonstrated a similar trend.

Sheiham and Sabbah [21] stated that levels of caries follow a predictable trend, provided stable environmental conditions and absence of any effective interventions [23]. In the present study, a large difference is observed in DMFT scores between adults and youngsters. This is in-line with similar findings in an Iranian study where higher age reported increase in caries experience [24]. Similar results were also reported in the northern and southern Indian study $[25,26]$. High DMFT scores among adults can also be accounted due to neglect from young individuals regarding their oral care, and it is only in later stages of life that carious lesion progresses to a significant level that an individual seeks dental assistance.

Caries is a multifactorial disease. Numbers of factors are responsible for initiation of dental caries such as composition and frequency of diet, socioeconomic status, salivary immunoglobulins, and bacterial and fluoride intake. Due to multiple etiologies, the study of dental caries has become complex. Apart from this, obesity and dental caries are complex conditions with etiological factors such as genetics, biological, behavioral, and environmental. BMI is used widely as a measurement tool for obesity due to the fact that it relates the height of a person with respect to his weight. It is also a tool for nutritional status indicator. Thus, it proves the fact that both dental caries and BMI are used as measurement tools for diet-related health outcomes. An association amongst them is not surprising.

Apart from this, malnourishment is also one of the etiologies for dental caries. Protein deficiency/energy loss leads to energy-protein malnourishment, reduction in the flow of saliva, formation of calculus, increase in carious lesions, and growth reduction. Studies have reported malnourishment in young adults predisposing to increase propensity to dental caries and salivary hypofunction [27].

The present study demonstrated statistically significant association between BMI and DMFT. A study by Elkhodary et al. reported significant association between more weight gain and dental caries [26]. Possible explanation can be the fact that obese individuals tend to consume high levels of soda and other sugary drinks and foods which by nature are obesogenic and cariogenic. Modéer et al. gave an opinion that overweight individuals have high caries risk as a result of reduction in the salivary flow rate, which itself is associated with protein-deficient malnourishment [27]. Contrary to these reported studies, Macek and Mitola reported the absence of any statistically significant association between age, BMI, and dental caries [28]. This clearly suggests that dental caries having multifactorial causes and associations can be as a result of similar trends observed in a specific population studied.

\section{Conclusion}

Although the exact nature of these associations is complex and can involve many other confounding variables that otherwise could affect the final outcome, the study has demonstrated that dental caries is influenced by factors such as age and BMI. Further studies on a much larger and diverse scale with factors such as socioeconomic status and dietary patterns will aid in further clarifying the risk factors of dental caries.

\section{Abbreviations}

DMFT: $\quad$ Decayed missing filled tooth

BMI: $\quad$ Body mass index

WHO: World Health Organization

OPD: $\quad$ Outpatient department

NHANES: National Health and Nutrition Examination Survey.

\section{Conflicts of Interest}

The authors declare that they have no conflicts of interest.

\section{Supplementary Materials}

"BMI DMFT Questionnaire" used in this study. (Supplementary Materials)

\section{References}

[1] World Health Organization, Obesity: Preventing and Managing the Global Epidemic (No. 894), World Health Organization, Geneva, Switzerland, 2000.

[2] A. Alm, H. Isaksson, C. Fahraeus et al., "BMI status in Swedish children and young adults in relation to caries prevalence," Swedish Dental Journal, vol. 35, no. 1, pp. 1-8, 2011.

[3] P. Yang, Y. Zhou, B. Chen et al., "Overweight, obesity and gastric cancer risk: results from a meta-analysis of cohort studies," European Journal of Cancer, vol. 45, no. 16, pp. 2867-2873, 2009. 
[4] S. J. Freedland, J. Wen, M. Wuerstle et al., "Obesity is a significant risk factor for prostate cancer at the time of biopsy," Urology, vol. 72, no. 5, pp. 1102-1105, 2008.

[5] N. T. Nguyen, C. P. Magno, K. T. Lane, M. W. Hinojosa, and J. S. Lane, "Association of hypertension, diabetes, dyslipidemia, and metabolic syndrome with obesity: findings from the National Health and Nutrition Examination Survey, 1999 to 2004," Journal of the American College of Surgeons, vol. 207, no. 6, pp. 928-934, 2008.

[6] F. Abbasi, B. W. Brown, C. Lamendola, T. McLaughlin, and G. M. Reaven, "Relationship between obesity, insulin resistance, and coronary heart disease risk," Journal of the American College of Cardiology, vol. 40, no. 5, pp. 937-943, 2002.

[7] A. O. Musaiger and M. A. Al-Mannai, "Weight, height, body mass index and prevalence of obesity among the adult population in Bahrain," Annals of Human Biology, vol. 28, no. 3, pp. 346-350, 2001.

[8] https://www.nidcr.nih.gov/DataStatistics/FindDataByTopic/ DentalCaries/DentalCariesAdults20to64.html.

[9] T. T. Amin, A. Al-Sultan, and A. Ali, "Overweight and obesity and their relation to dietary habits and socio-demographic characteristics among male primary school children in Al-Hassa, Kingdom of Saudi Arabia," European Journal of Nutrition, vol. 47 , no. 6 , pp. 310-318, 2008.

[10] J. Kearney, "Food consumption trends and drivers," Philosophical Transactions of the Royal Society of London B: Biological Sciences, vol. 365, no. 1554, pp. 2793-2807, 2010.

[11] H. Prakash, S. S. Sidhu, and K. R. Sundaram, "Prevalence of dental caries among Delhi school children," Journal of the Indian Dental Association, vol. 70, pp. 12-14, 1999.

[12] R. A. Bagramian, F. Garcia-Godoy, and A. R. Volpe, "The global increase in dental caries. A pending public health crisis," American Journal of Dentistry, vol. 22, no. 1, pp. 3-8, 2009.

[13] http://www.aihw.gov.au/media-release-detail/?id=60129546452.

[14] P. E. Petersen, D. Bourgeois, H. Ogawa, S. Estupinan-Day, and C. Ndiaye, "The global burden of oral diseases and risks to oral health," Bulletin of the World Health Organization, vol. 83, no. 9, pp. 661-669, 2005.

[15] World Health Organization, Oral Health Surveys: Basic Methods, World Health Organization, Geneva, Switzerland, 2013.

[16] K. Alswat, W. S. Mohamed, M. A. Wahab, and A. A. Aboelil, "The association between body mass index and dental caries: cross-sectional study," Journal of Clinical Medicine Research, vol. 8, no. 2, pp. 147-152, 2016.

[17] M. L. Booth, T. Dobbins, A. D. Okely, E. Denney-Wilson, and L. L. Hardy, "Trends in the prevalence of overweight and obesity among young Australians, 1985, 1997, and 2004," Obesity, vol. 15, no. 5, pp. 1089-1095, 2007.

[18] B. A. Dye, J. D. Shenkin, C. L. Ogden, T. A. Marshall, S. M. Levy, and M. J. Kanellis, "The relationship between healthful eating practices and dental caries in children aged 2-5 years in the United States, 1988-1994," Journal of the American Dental Association, vol. 135, no. 1, pp. 55-66, 2004.

[19] http://www.huffingtonpost.com/sam-cohen/obesity-in-the-usand-eur_b_9845182.html.

[20] M. Carroll, K. Flegal, B. Kit, and C. Ogden, "Prevalence of obesity among adults: United States, 2011-2012," American Medical Association, vol. 311, no. 8, 2013.

[21] A. Sheiham and W. Sabbah, "Using universal patterns of caries for planning and evaluating dental care," Caries Research, vol. 44, no. 2, pp. 141-150, 2010.

[22] F. Eslamipour, A. Borzabadi-Farahani, and I. Asgari, "The relationship between aging and oral health inequalities assessed by the DMFT index," European Journal of Paediatric Dentistry, vol. 11, no. 4, p. 193, 2010.

[23] K. Bauba, A. Tewari, and H. S. Chawla, "Frequency distribution of children according to dental caries status in rural areas of northern India (Punjab)," Journal of the Indian Dental Association, vol. 58, no. 12, p. 505, 1986.

[24] A. Rao, S. P. Sequeira, and S. Peter, "Prevalence of dental caries among school children of Moodbidri," Journal of the Indian Society of Pedodontics and Preventive Dentistry, vol. 17, no. 2, pp. 45-48, 1999.

[25] W. J. Psoter, B. C. Reid, and R. V. Katz, "Malnutrition and dental caries: a review of the literature," Caries Research, vol. 39, no. 6, pp. 441-447, 2005.

[26] H. Elkhodary, D. Farsi, L. Merdad et al., "Prevalence of obesity among preschool children and its relation with dental caries," Journal of Dentistry and Oral Hygiene, vol. 9, no. 1, pp. 1-7, 2017.

[27] T. Modéer, C. C. Blomberg, B. Wondimu, A. Julihn, and C. Marcus, "Association between obesity, flow rate of whole saliva, and dental caries in adolescents," Obesity, vol. 18, no. 12 , pp. 2367-2373, 2010.

[28] M. D. Macek and D. J. Mitola, "Exploring the association between overweight and dental caries among US children," Pediatric Dentistry, vol. 28, no. 4, pp. 375-380, 2006. 


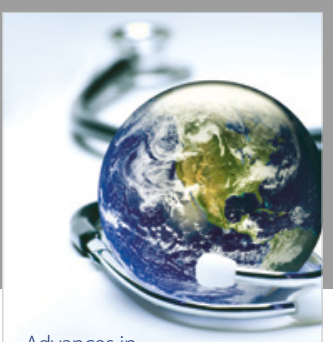

Advances in
Public Health

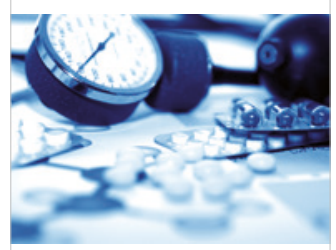

Case Reports in

Medicine

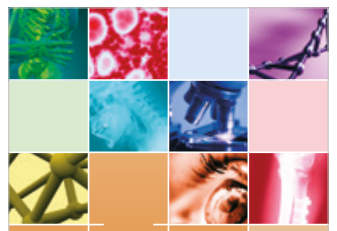

niernational Journal of

Biomaterials
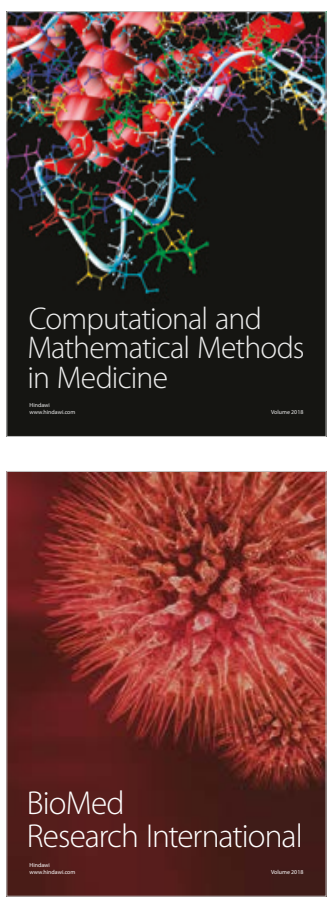

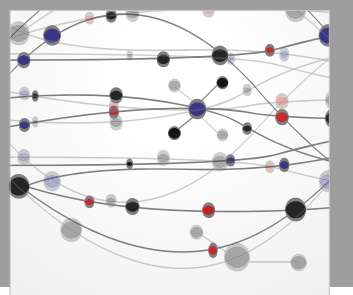

The Scientific World Journal Dentistry

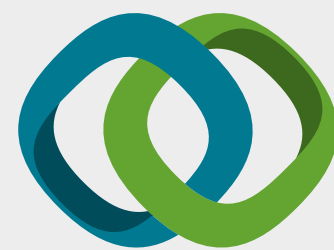

Hindawi

Submit your manuscripts at

www.hindawi.com
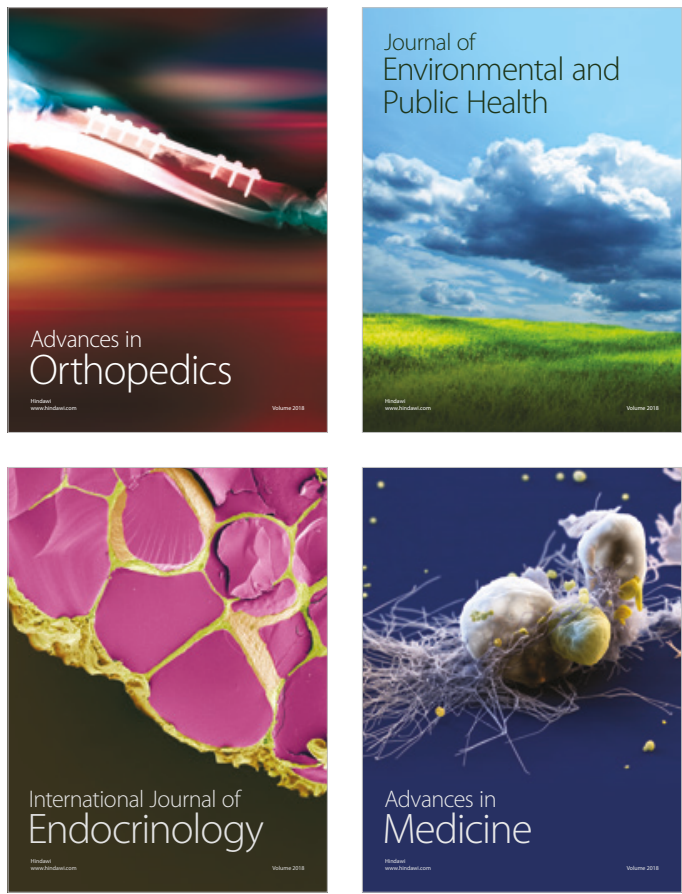
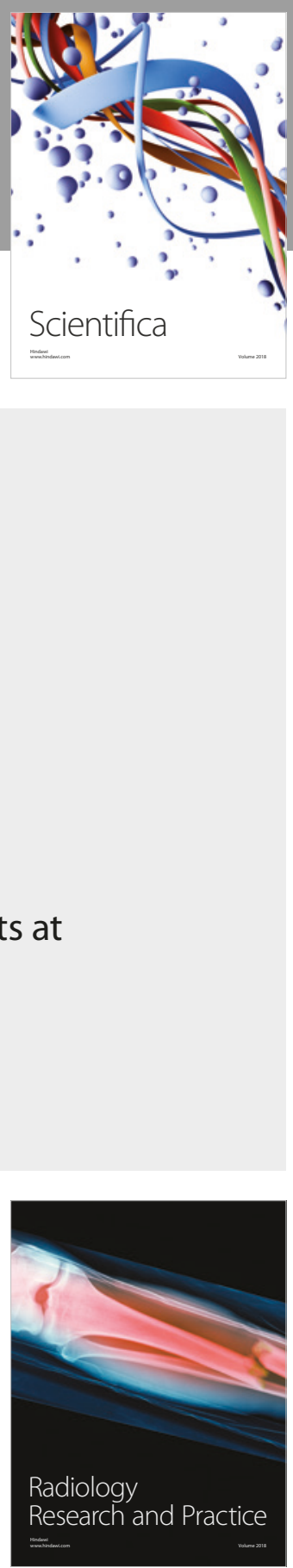

Scientifica

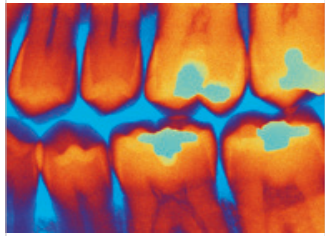

Case Reports in

Dentistry
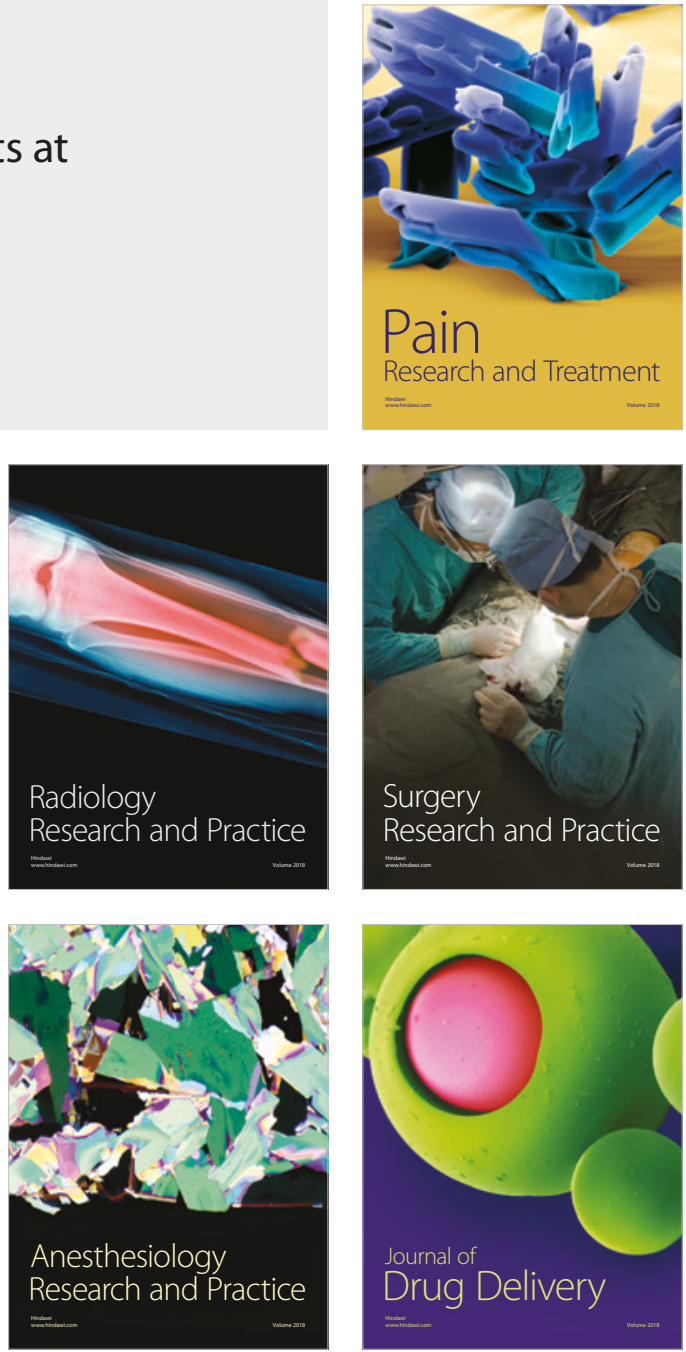